Portland State University

PDXScholar

1982

\title{
Phonational frequency ranges in vocally untrained adults using different cardinal vowels
}

Lorie Renee Chambers

Portland State University

Follow this and additional works at: https://pdxscholar.library.pdx.edu/open_access_etds

Part of the Phonetics and Phonology Commons, and the Speech Pathology and Audiology Commons Let us know how access to this document benefits you.

\section{Recommended Citation}

Chambers, Lorie Renee, "Phonational frequency ranges in vocally untrained adults using different cardinal vowels" (1982). Dissertations and Theses. Paper 3171.

https://doi.org/10.15760/etd.3160

This Thesis is brought to you for free and open access. It has been accepted for inclusion in Dissertations and Theses by an authorized administrator of PDXScholar. Please contact us if we can make this document more accessible: pdxscholar@pdx.edu. 
An ABSTRACT OF THE THESIS OF Lorie Renee Chambers for the Master of Science in Speech Pathology and Audiology presented June 3, 1982 .

Title: Phonational Frequency Ranges in Vocally Untrained Adults Using Different Cardinal Vowels

APPROVED BY MEMBERS OF THE THESIS COMMITTEE:

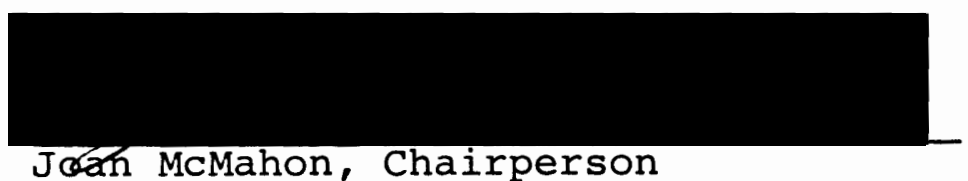

Joan McMahon, Chairperson
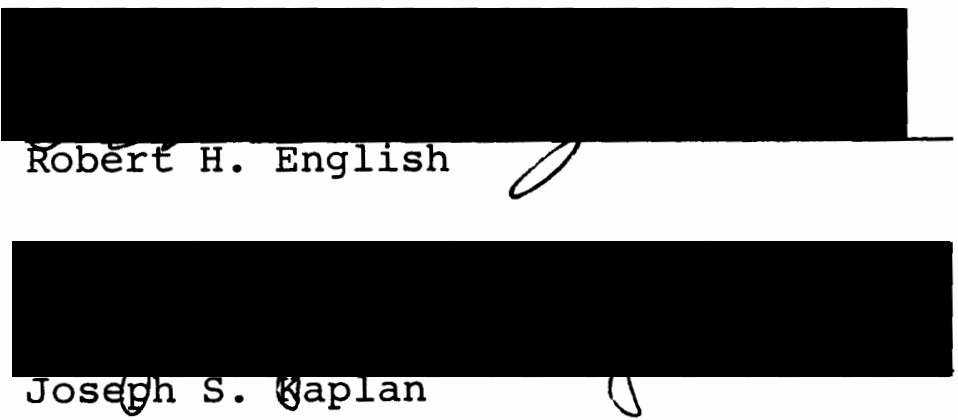

In the clinical management of voice clients, it is important to measure accurate pitch ranges in order to determine if a client has a normal range or is speaking at an optimum pitch. It is not clear from the literature which vowel should be used in determining these pitch ranges. The purpose of this investigation was to determine the phonational frequency ranges in adults with no vocal training when 
phonating the cardinal vowels of $/ i /, / u /$, and $/ a /$. The investigation sought to answer the following question: Does the phonational frequency range in vocally untrained adults vary significantly when phonating the cardinal vowels of $/ i /$, $/ \mathrm{u} /$, and $/ a /$ ?

Twenty-four men and twenty-four women between the ages of twenty and twenty-nine years (mean age 24.1 years), served as subjects. All subjects had voices within the normal range of acceptability and had normal hearing.

The subjects were instructed to sing the musical scale to their lowermost (excluding vocal fry) and uppermost (including falsetto) limits and to sustain their lowest and highest notes for four seconds. The extremes of the ranges were audio-recorded and analysed by an oscilloscope and fast Fourier transform spectrum analyser for exact frequencies.

Results from this investigation revealed no statistically significant differences existed between the extent of the phonational frequency ranges by varying the vowel for either sex group; however, in the female group, the difference between the extent of the ranges for $/ i /$ and $/ a /$ showed a trend toward significance as the level of significance between these two vowels reached .055 (p<.05) (d.f.=23).

The males' mean PFR using / $i /$ extended from $89 \mathrm{~Hz}$ to $661 \mathrm{~Hz}$, or about $F_{2}$ to $E_{5}$ for a mean range of three octaves (thirty-six semitones). Their mean PFR using / $/$ / extended from $90 \mathrm{~Hz}$ to $645 \mathrm{~Hz}$, or about $\mathrm{F}_{2}$ to $E_{5}$ for a mean range of 
three octaves (thirty-six semitones). The mean PFR using /a/ extended from $88 \mathrm{~Hz}$ to $656 \mathrm{~Hz}$, again about $\mathrm{F}_{2}$ to $\mathrm{E}_{5}$ for a mean range of three octaves (thirty-six semitones).

The females' mean PFR using / $i /$ extended from $161 \mathrm{~Hz}$ to $111 \mathrm{~Hz}$, or about $E_{3}$ to $C_{6}$ for a mean range of slightly more than two and one-half octaves (thirty-two semitones). Their mean PFR using / $\mathrm{u} /$ extended from $162 \mathrm{~Hz}$ to $1051 \mathrm{~Hz}$, or about $E_{3}$ to $C_{6}$ for a mean range of slightly more than two and onehalf octaves (thirty-two semitones). The mean PFR using /a/ extended from $157 \mathrm{~Hz}$ to $1016 \mathrm{~Hz}$, again about $E_{3}$ to $\mathrm{C}_{6}$ for a mean range of two and one-half octaves (thirty-two semitones). Data were also collected on natural pitch levels, although not a part of the original investigation. Natural pitch levels for males ranged from $A_{2}{ }_{2}$ to $G_{3}$ for all vowels with a mean natural pitch level at $\mathrm{D}_{3}$ for all vowels.

Natural pitch levels for females ranged from $\mathrm{G}_{3}$ to $\mathrm{D}_{4}$ for all vowels with a mean natural pitch level at $c_{4}$ for $/ i /$ and at $\mathrm{B}_{3}$ for $/ \mathrm{u} /$ and $/ \mathrm{a} /$. 
PHONATIONAL FREQUENCY RANGES IN VOCALLY UNTRAINED ADULTS USING DIFFERENT CARDINAL VOWELS

by

LORIE RENEE CHAMBERS

A thesis submitted in partial fulfillment of the requirements for the degree of

MASTER OF SCIENCE IN SPEECH COMMUNICATION:

with an emphasis in

SPEECH PATHOLOGY/AUDIOLOGY

Portland State University

1982 
TO THE OFFICE OF GRADUATE STUDIES AND RESEARCH:

The members of the Committee approve the thesis of Lorie Renee Chambers presented June 3, 1982.

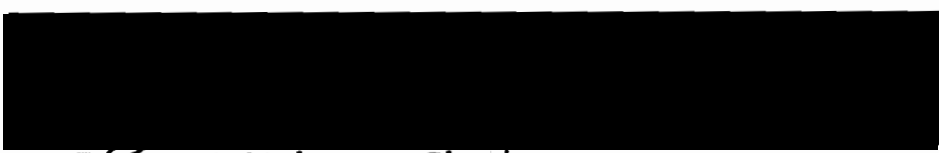

Jean McMahon, Chairperson
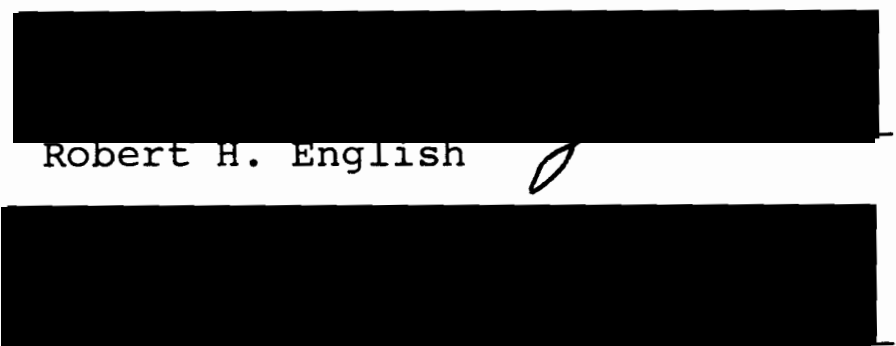

Joseph \$. Kaplan

()

APPROVED :

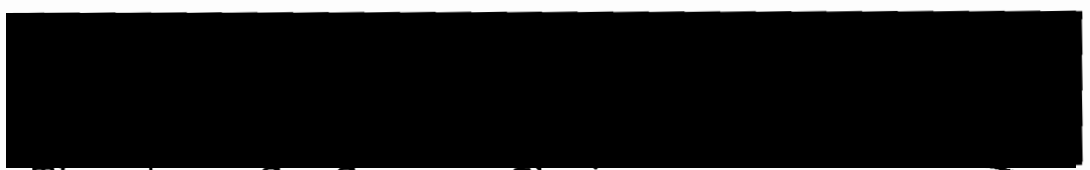

Theodore G. Grove, Chair

Department of Speech Communication

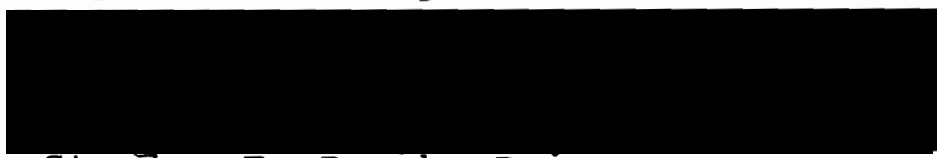

stanley E. Rauch, Dean,

Graduate Studies and Research 
TABLE OF CONTENTS

Page

IIST OF TABLES $\quad \ldots \ldots \ldots \ldots \ldots \ldots \ldots \ldots \ldots \ldots \ldots \ldots \ldots \ldots$

IIST OF FIGURES $\ldots \ldots \ldots \ldots \ldots \ldots \ldots \ldots \ldots \ldots \ldots \ldots \ldots$ vi

CHAPTER

I INTRODUCTION 1

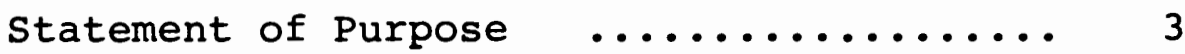

Operational Definitions $\ldots \ldots \ldots \ldots \ldots \ldots . . .3$

II REVIEW OF THE LITERATURE 5

Overview of Pitch, Vowels, and Laryngeal

Musculature Action $\quad . \ldots \ldots \ldots \ldots \ldots \ldots \ldots$

The Pitch-Changing Mechanism .......

Cardinal Vowels and Laryngeal Muscula-

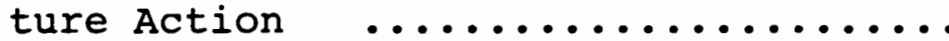

Phonational Frequency Ranges .......... 9

III METHODS AND PROCEDURES 16

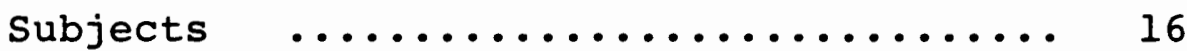

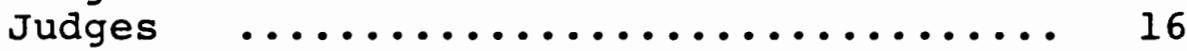

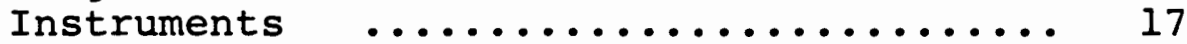

Test Instruments $\ldots \ldots \ldots \ldots \ldots \ldots \ldots 17$

Electronic Instruments ........... 18

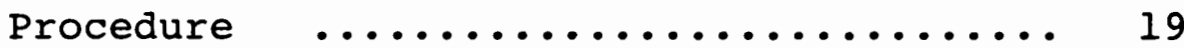

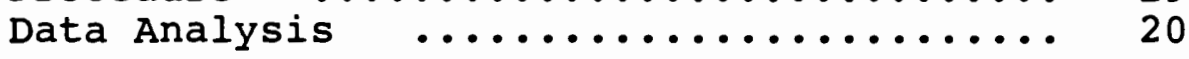

IV RESULTS AND DISCUSSION 22

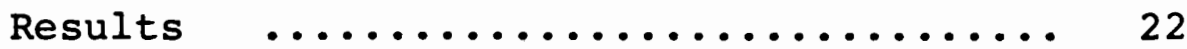

Phonational Frequency Ranges ...... 22

Natural Pitch Levels ............ 26

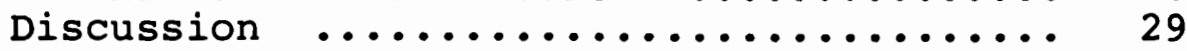

Phonational Frequency Ranges ...... 29

Natural Pitch Levels ............ 32

V SUMMARY AND IMPLICATIONS 34

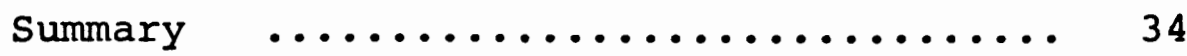


Page

Implications

clinical

Research

BIBLIOGRAPHY 


\section{LIST OF TABLES}

TABLE

Page

I Comparison of Mean Phonational Frequency

Ranges Reported in $\mathrm{Hz}$

II Phonational Frequency Ranges by Extent, Means, S.D., Musical Note, Octaves, and Semitones ... 24

II Combined Mean Ranges for Both Sex Groups .... 27

IV Natural Pitch Level Modes and Number of Subjects for Each Note, by Vowel ................. 28

$V$ Comparisons of Phonational Frequency Ranges in Octaves and Semitones According to Various Studies 


\section{LIST OF FIGURES}

FIGURE

Page

1. Cardinal Vowels and Tongue Position 


\section{CHAPTER I}

\section{INTRODUCTION}

The normal human range of laryngeal frequencies encompasses at least two octaves (Brodnitz, 1959; Hollien, 1977). It is important to determine ranges for clinical purposes, such as determining if a client has a normal range and also if a client is speaking at an optimal pitch.

Normal functioning human vocal organs are capable of producing a wide range of frequencies or pitches. Various frequencies are produced when a steady air stream is exhaled from the lungs and sound waves are generated by the vibrations of the vocal folds which are housed in the larynx. Frequency is determined by the mass, tension, length, and elasticity of the vocal folds (Zemlin, 1981) and is discussed in terms of cycles per second (cps) or Hertz (Hz). Vowels also may be a determinant of frequency as laryngeal muscles have varied action during vowel production (Negus, 1930; Husler and Rodd-Marling, 1964; Vennard, 1967). Pitch is the psychological perception of frequency and is discussed in terms of musical scale units such as the semitone, tone, or octave (Hanley and Thurman, 1962).

The range of frequencies humans can produce has been reported in the literature by various authors (Anderson, 1942; 
Brodnitz, 1959; Fairbanks, 1960; Hollien, 1960; Hollien, 1962; Luchsinger and Arnold, 1965; Ptacek et al., 1966; Appelman, 1967; Meano and Khoury, 1967; Vennard, 1967; Hollien and Michel, 1968; Boone, 1971; Hollien, Dew, and Philips, 1971; Shipp and McGlone, 1971; Anderson, 1977; Hollien, 1977; Zemlin, 1981). Of interest to this examiner was phonational frequency range (PFR) described by Hollien (1977). The extent of PFR's has been cited for adults and has been reported to extend two octaves (Anderson, 1942; Brodnitz, 1959). Ptacek et al. (1966) reports this range for older adults. Two and one-half octaves have been reported for younger adults (Ptacek et al., 1966). Shipp and McGlone (1971) report two and one-half octaves for younger males. Hollien (1962) cites three octaves for males while Hollien, Dew, and Philips (1971) report this range for both males and females. Hollien (1960), Appelman (1967), Meano and Khoury (1967), Vennard (1967), and Anderson (1977) report a PFR of four octaves while Hollien (1962) reports this range for females. Brodnitz (1959) and Luchsinger and Arnold (1965) state that trained singers have ranges of three or more octaves. According to Brodnitz (1959), the combined range for males and females encompasses four octaves while zemlin (1981) reports this combined range to encompass five and one-half octaves. Some of these authors reported vocal training of the subjects while others did not. Some reported the vowel used in determining these ranges while others did not. Only in 
the study reported by Hollien, Dew, and Philips (1971) was vocal training and the vowel being phonated specified. In order to more accurately determine the phonational frequency range in vocally untrained adults, it is important to examine the effect of different vowels on the extent of the phonational frequency range.

\section{Statement of Purpose}

The purpose of this investigation was to determine the phonational frequency range in adults with no vocal training when phonating the cardinal vowels of $/ i /, / u /$, and $/ a /$. The investigation sought to answer the following question:

Does the phonational frequency range in vocally untrained adults vary significantly when phonating the cardinal vowels of $/ i /, / u /$, and $/ a /$ ?

\section{Operational Definitions}

Phonation - the production of sound waves (fundamental frequencies) which occurs when the vocal folds are set into vibration.

Register - a range of frequencies whose quality does not change from the lowest to the highest note in that particular register. There are three voice registers:

1) pulse or glottal fry which includes the lowest range of frequencies, 2) modal which includes the middle range of frequencies normally used in speaking and singing, and 3) falsetto or loft which includes the highest range of frequencies. 
Phonational Frequency Range (PFR) - ". . the extent of the modal and loft registers . . determined by the lowest sustainable frequency in the modal register and the highest sustainable frequency in the loft register (Hollien, 1977)."

Nonclinical - a voice sample subjectively judged not to be in need of voice management as based on the overall severity rating on the Jewish Hospital Voice Profile (Wilson, 1971). Voices judged to be nonclinical would receive ratings from 1.0 to 3.5 .

Clinical - a voice sample subjectively judged to be in need of voice management as based on the overall severity rating on the Jewish Hospital Voice Profile (Wilson, 1971). Voices judged to be clinical would receive ratings from 4.0 to 7.0 . 
CHAPTER II

REVIEW OF THE LITERATURE

Speech has been described as an overlaid function. This means the human vocal mechanism has a non-biological function (i.e., speech) as well as a biological function (i.e., protection of the respiratory tract). Speech has been described as having four phases: respiration, phonation, resonation, and articulation (zemlin, 1981). Singing (prolonging phonation of sounds at specific frequencies) also may be described as an overlaid function (Appelman, 1967). The four phases used to describe speech also apply to this type of vocal production.

Prior to presenting empirical research on phonational frequency ranges, a brief overview of the pitch-changing mechanism, cardinal vowels, and laryngeal musculature action in the production of vowels will be discussed.

\section{Overview of Pitch, Vowels, and Laryngeal} Musculature Action

The Pitch-Changing Mechanism

Changes in pitch occur when the mass, tension, length, or elasticity of the vocal folds is changed (zemlin, 1981). As the length of the vocal folds increases or decreases, mass is reduced or increased and there is a resultant raising or 
lowering of pitch.

Pitch is raised by the intrinsic muscle interactions of the cricothyroid, the thyroarytenoid, and to a lesser extent, the posterior cricoarytenoid muscles (Zemlin, 1981). Pitch is lowered by the interactions of the thyrovocalis and thyromuscularis portions of the thyroarytenoid muscle. Extrinsic muscles of the larynx are active in the production of laryngeal frequencies at both the low and high ends of the pitch range (Zemlin, 1981).

The laryngeal muscles involved in controlling pitch function through complex interactions with one another. Specific laryngeal muscles also are believed to function in the production of vowels. What follows is a discussion of vowels and laryngeal musculature action in the production of vowels.

Cardinal Vowels and Laryngeal Musculature Action in the Production of Vowels

Just as there are specific muscles that control pitch, there are specific muscles that are active in the production of vowels. Before describing the laryngeal musculature action of vowels, a general description of cardinal vowels will be presented.

Tongue position plays a major role in the production of vowels. The position of the tongue is usually described in reference to the highest part of the tongue's main body. There are specific reference points within the oral cavity and the vowels produced when the tongue is positioned at these points are called cardinal vowels. Cardinal vowels are 
defined by Denes and Pinson (1963) as ". . a set of standard reference sounds whose quality is defined independently of any lanugage." Jones (1960) describes these vowels as a series of ". . acoustically equidistant vowels." Cardinal vowels are discussed as follows: 1) the main body of the tongue is in a high, mid, or low position in the oral cavity; and 2) the main body of the tongue is positioned front, central, or back in the oral cavity (Leutenegger, 1963). The vowels produced also are referred to as: 1) close, when the tongue is at the bottom of the mouth (Denes and Pinson, 1963); and 2) tense or lax depending on the degree of muscular tension in the tongue (Leutenegger, 1963). According to Leutenegger (1963), lip rounding is related to tongue position in the production of vowels. Front vowels are unrounded, while back vowels, except $/ a /$, are rounded. The vowel /i/ is a tense, unrounded, high-front close vowel; /u/ is a tense, rounded, high-back close vowel, and /a/ is a lax, unrounded, low-back open vowel. There are eight cardinal vowels as shown in Figure 1.

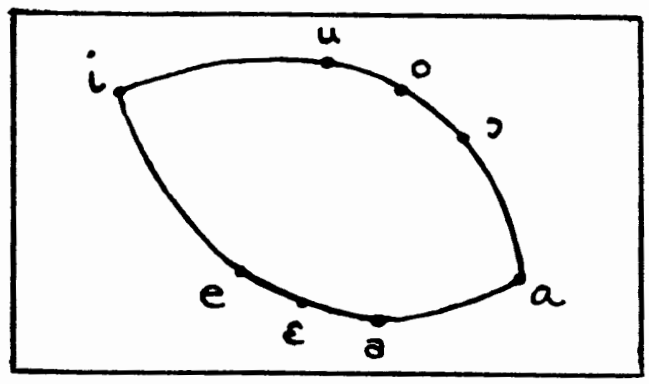

Figure 1. Cardinal vowels and tongue position (Jones, 1960). 
As previously stated, the vocal tract with its resonating properties, and the articulators, specifically the tongue and lips, are active in the production of vowel sounds. Laryngeal musculature also functions in the production of vowels (Negus, 1930; Husler and Rodd-Marling, 1964; Vennard, 1967).

Negus (1930) reports that vowels are produced at the level of the larynx during whispered speech in addition to their production through changes in the configuration of the vocal tract. He describes the margins of the glottis during whispered /a/ and /i/, stating that during whispered /a/ the glottis is more open than during whispered /i/ where the margins of the glottis are almost or completely in contact with each other. No information was provided on laryngeal musculature action during phonation.

Husler and Rodd-Marling (1964) describe laryngeal musculature action for the vowels $/ i /, / u /$, and $/ a /$. These authors state that during phonation of /i/, the cricothyroid, posticus, lateralis, and transversus muscles are active. During phonation of $/ u /$, the larynx is pulled forward and simultaneously drawn slightly upward posteriorly by the palato-laryngeal muscles. During phonation of $/ a /$, the margins of the golottis are completely closed by the action of the aryvocalis and thyrovocalis muscles.

According to Vennard (1967), "round" (1ip-rounded) vowels (i.e., $/ u /$ ) tend to lower the larynx. He further states that higher pitches may be reached with "round" vowels as 
opposed to "pointed" (unrounded) vowels.

These authors have provided limited and varied information on laryngeal musculature functioning during vowel production. Because it appears that different muscles are active during the production of vowels, it may be an important variable to consider which vowel is phonated when determining phonational frequency ranges. Phonational frequency ranges have been studied by various researchers and a review of their findings will now be presented.

\section{Phonational Frequency Ranges}

Phonational frequency ranges have been described by various phrases such as total pitch range (Fairbanks, 1960), musical range (Luchsinger and Arnold, 1965), and pitch range (Boone, 1971). All of these phrases refer to a common entity. Much of the information on vocal ranges has been limited and contradictory in that the vowel used in determining phonational frequency range was not reported. Some researchers did not report if the subjects had received formal training in vocal music. Some information is contradictory concerning the extent of the ranges. Despite the lack of these important pieces of information and the lack of consistency of findings, the data provided allows for some comparisons to be made. For example, Anderson (1942) and Brodnitz (1959) state that the untrained singing voice has a range of about two octaves (twenty-four semitones). Brodnitz (1959) and Luchsinger and Arnold (1965) report that trained singers have 
ranges of three or more octaves (thirty-six or more semitones). Anderson (1977), Vennard (1967), and Appelman (1967) report that the PFR extends about four octaves (forty-four semitones). Meano and Khoury (1967) also report a range of about four octaves but slightly greater (forty-eight semitones). According to Brodnitz (1959), the combined male and female PFR extends four octaves (forty-eight semitones) while Zemlin (1981), in contrast, reports a combined male and female PFR of about five and one-half octaves (sixty-eight semitones).

Some researchers have determined PFR's not as the main purpose of their research but as a part of other investigative measures. For example, Hollien (1960) investigated laryngeal dimensions and part of the research included determining the PFR's of twelve males and twelve females ranging in age from eighteen to twenty-nine years. These subjects had no formal vocal training, exhibited no speech or voice defects, and were able to sing the musical scale with ease. For purposes of his study, only those subjects who individually had ranges of two and one-half to slightly over three octaves (thirty to thirty-six semitones) were included. The collective PFR's of the males and females ranged about four octaves (forty-six semitones) for each sex group. The vowel phonated was not specified.

In a similar study by Hollien (1962), three males and three females ranging in age from nineteen to thirty-three years, served as subjects. The same criteria for inclusion 
in the study was that set forth by Hollien (1960). The collective PFR's for the males ranged slightly more than three octaves (forty semitones) while the collective PFR's for the females ranged about four octaves (forty-four semitones). Again, the vowel phonated was not specified.

Shipp and McGlone (1971) measured laryngeal muscle activity, subglottal pressure, and air flow as fourteen young adult males sustained phonation of $/ a /$ at specific intervals of their PFR's. These subjects exhibited a collective and mean PFR of approximately three octaves, forty-one semitones and thirty-two semitones, respectively. Vocal training was not specified.

Ptacek et al. (1966) investigated changes in performance on various tasks as a function of advanced age. One task involved determining the frequency range (including the pulse register) of subjects under forty years and subjects over sixty-five years. Thirty-one males, ranging in age from eighteen to thirty-nine years (mean 27.6 years), and thirtyone females, ranging in age from eighteen to thirty-eight years (mean 23.5 years), served as subjects for the younger group. In the older group, twenty-seven males, ranging in age from sixty-eight to eighty-nine years (mean 76.9 years), and thirty-six females, ranging in age from sixty-six to ninety-three years (mean 76.9 years), served as subjects. By earphone, each subject was presented a tape recorded pure tone having a duration of two seconds. The subjects were to match each tone by phonating $/ a /$. The tones were 
presented first in a descending, then ascending order to determine the lowest and highest pitches, again including the pulse register. The Purdue Pitch Meter was used to determine pitch levels.

The frequency range for the young males extended about two and one-half octaves with a range of twenty-three to forty-seven semitones and a mean of 34.5 semitones. The frequency range for the older males extended about two octaves with a range of eleven to thirty-five semitones and a mean of 26.5 semitones. The young females' frequency range extended about two and one-half octaves with a range of twenty to forty semitones and a mean of 32.8 semitones. The frequency range for the older females extended about two octaves with a range of nine to forty-one semitones and a mean of 25.1 semitones. According to Ptacek et al. (1966), these results indicate a significant reduction in frequency range with advanced age as the younger subjects phonated, on the average, about four tones higher and greater than the older subjects. Again, in this study, vocal training was not specified.

Hollien and Michel (1968) conducted a frequency range study on the three laryngeal registers, studying in particular the pulse (vocal fry) register. Twelve normal male and eleven normal female adults, twenty to thịty-five years of age, were instructed to phonate $/ a /$ at a fundamental frequency that matched the frequency of audio-recorded slow and fast pulses produced by a square wave generator. The subjects were instructed to produce vocal fry at the slowest, then 
fastest repetition rates possible. These phonations were recorded and converted into phonellegrams for fundamental frequency measurements.

Results of this study revealed the group range for males phonating in vocal fry extended slightly more than two octaves (twenty-eight semitones) while the mean pulse range extended slightly more than one octave (fourteen semitones). Modal and falsetto ranges also were obtained. The group modal range extended three octaves (thirty-six semitones) while the mean modal range extended about one and one-half octaves (nineteen semitones). The group falsetto range extended about two octaves (twenty-seven semitones) while the mean falsetto range extended slightly more than one octave (fourteen semitones).

The group range for females phonating in vocal fry extended slightly more than two octaves (twenty-eight semitones) while the mean pulse range extended nearly one and one-half octaves (seventeen semitones). The group modal range extended almost three octaves (thirty-two semitones) while the mean modal range extended about two and one-half octaves (twentynine semitones). The group falsetto range extended three octaves (thirty-six semitones) while the mean falsetto range extended slightly more than one octave (fifteen semitones). Vocal training was not specified.

Hollien, Dew, and Philips (1971) studied the PFR of vocally untrained men and women. These researchers gathered normative data on 332 males and 202 females who met the same 
criteria set forth by Hollien (1960). The age ranges for both sexes was eighteen to thirty-six years with a mean age of 21.4 years for the males and 22.8 years for the females. Phonational frequency range was determined by the same procedures outlined by Hollien and Michel (1968). They concluded that the group range for males extended slightly over one octave (thirteen semitones) to over four and one-half octaves (fifty-five semitones). The mean range extended slightly over three octaves (thirty-eight semitones). The group range for females extended from two octaves (twenty-three semitones) to over four octaves (fifty semitones). The mean range extended slightly over three octaves (thirty-seven semitones). After comparing these findings with previous findings of the PFR's for trained singers, these authors concluded that many untrained singers have ranges that are just as extensive as trained singers. They also found no trends or differences related to age at the extreme boundaries of the age range studied.

Reviewing the data on the studies reported by Hollien, Dew, and Philips (1971), Shipp and McGlone (1971), Hollien and Michel (1968), Ptacek et al. (1966), Hollien (1962), and Hollien (1960), this examiner noted that not all of the researchers reported the vowel used in determining the ranges; nor did they all report the vocal training of the subjects. only in the normative study by Hollien, Dew, and Philips (1971) was the vowel and vocal training reported; therefore, 
this examiner believed there was a need to investigate the effect of vowels on phonational frequency ranges in adults having no vocal training. 
CHAPTER III

METHODS AND PROCEDURES

Subjects

Forty-eight subjects, twenty-four men and twenty-four women, between the ages of twenty and twenty-nine years (mean age 24.1 years for both sex groups), were selected to participate in this study. The subjects were Portland State university students or residents of the Portland metropolitan area.

Each subject passed a subject eligibility screening shown in Appendix A. All subjects had voices within the normal range of acceptability determined by this examiner based on the overall severity rating on the Jewish Hospital Voice Profile (Wilson, 1971) shown in Appendix B. Subjects had normal hearing sensitivity as determined by a bilateral air conduction screening test at $25 \mathrm{~dB}$ HL for the frequencies of $250-8000 \mathrm{~Hz}$.

\section{Judges}

Two judges and this examiner, who had completed Voice Theory and Practicum at Portland State University, rated twenty audio-recorded voice samples of Portland State University students enrolled in Voice and Diction classes during 
Fall Term, 1981. Voice samples were taken by recording the "Rainbow Passage (Fairbanks, 1960)." A training session was held and the judges subjectively rated the voice samples as either clinical or nonclinical as based on the overall severity rating on the Jewish Hospital Voice Profile (Wilson, 1971). Interjudge reliability of 90 percent was achieved. Intrajudge reliability of 90 percent was achieved by the examiner ten days after the original training session by rating the same recordings.

Reliability of the examiner's ability to determine the phonational frequency ranges using the Fairbanks (1960) method was established by achieving interjudge reliability of 90 percent. This was accomplished by recording and determining the phonational frequency ranges of ten non-participants of the study by this examiner and a graduate student trained in the Fairbanks (1960) method. Intrajudge reliability of 90 percent was achieved by this examiner ten days after interjudge reliability was established by rating the same recordings.

\section{Instruments}

\section{Test Instruments}

The Fairbanks (1960) method was used to determine phonational frequency ranges and natural pitch levels. The method involves first singing down the musical scale to one's lowest note, then singing up the scale to one's highest note, including falsetto. Each of these notes (the lowest and 
highest) are plotted on the Musical Scale Pitch Level Comparison shown in Appendix C. Natural pitch level is estimated by drawing a straight line to connect the lowest and highest notes on the two outer scales. Where the line intersects with the middle scale is the estimated natural pitch level. The Jewish Hospital Voice Profile (Wilson, 1971) was used as a basis to distinguish voice samples that were subjectively judged to be clinical from those subjectively judged to be nonclinical. The major vocal parameters rated on the scale include laryngeal openness, pitch, and resonance. Scale A, concerning laryngeal openness, ranges from -4 (vocal folds totally open) to +3 (vocal folds closed and extremely tensed). Scale B, concerning pitch, ranges from -3 (deviantly low pitch) to +3 (deviantly high pitch). Scale C, concerning nasal resonance, ranges from -2 (lack of nasal resonance on normally nasalized sounds) to +4 (nasal resonance on all sounds). A rating of one on these three parameters indicates a voice within normal limits. An overall severity rating scale ranging from one to three and one-half was designated as nonclinical and a rating ranging from four to seven was designated as clinical for purposes of this study.

\section{Electronic Instruments}

The Beltone portable audiometer, Model 10-D, and TDH-39 air receivers with $M X-41 / A R$ cushions were used to screen bilateral hearing sensitivity at $25 \mathrm{~dB} \mathrm{HL}$ for the frequencies of 250-8000 Hz. A tuned piano was used to accompany the 
subjects in singing their phonational frequency ranges. The Ampex AG-500 reel-to-reel tape recorder and the Electro-Voice Dynamic Omnidirectional microphone, Model $635 \mathrm{~A}$, were used to record the subjects' trials of sustaining their lowest and highest notes. In conjunction with the Ampex AG-500 recorder and the Ampex 622 pre-amplifier, the Tektronix portable oscilloscope, No. 485, and the Princeton Applied Research fast Fourier transform (FFT) Spectrum Analyser, No. 4512, were used to determine the fundamental frequencies (or "first harmonic") of the sustained vowels. Using Scale A of the General Radio sound level meter, No. 1563, the level of ambient room noise was determined for the music module where the study was conducted. The Jaxon Timer stopwatch, No. 3102, was used to measure a four-second period of the sustained lowest and highest notes. Refer to Appendix E for the specifications for the recorder, oscilloscope, and spectrum analyser.

\section{$\underline{\text { Procedure }}$}

The subjects reported to a music module, Lincoln Hall, Department of Music, Portland State University where ambient room noise, as measured by the sound level meter, fluctuated between $20 \mathrm{~dB}$ SPL and $50 \mathrm{~dB}$ SPL. Upon passing the subject eligibility screening, each subject read the first paragraph of the "Rainbow Passage (Fairbanks, 1960)" shown in Appendix D. The voice samples were analysed at the time the samples 
were taken by this examiner. Each subject then passed the hearing screening.

With the accompaniment of the piano, the subjects were instructed to sing the musical scale to their lowermost (excluding vocal fry) and uppermost (including falsetto) limits and to sustain their lowest and highest notes for four seconds upon command of this examiner. This procedure was repeated for each of the three vowels. Two trials were given for each vowel. Only the extremes of the ranges for all trials were audio-recorded. In order to allow for purity of the sustained vowels on audio tape, the piano tones were damped while the lowest and highest notes were being sustained. Each sex group was randomly divided into three sub-groups of eight subjects each and the subjects were instructed as to which order to sing the vowels. The order of vowel presentation varied in the following manner:

\begin{tabular}{|c|c|c|}
\hline Group 1 & $/ i /$ & $/ \mathrm{u} /$ \\
\hline Group 2 & $/ u /$ & $|a|$ \\
\hline roup & $|a|$ & $/ i /$ \\
\hline
\end{tabular}

Data Analysis

A two-tailed $\underline{t}$-test was used to determine if a statistically significant difference existed between the extent of the phonational frequency ranges when the subjects phonated $/ i /, / u /$, and /a/ (i.e., comparing the ranges of /i/ to /u/, $/ i /$ to $/ a /$, and $/ \mathrm{u} /$ to $/ a / /$.

The CONDESCRIFTIVE subprogram of the Statistical Package 
for the Social Sciences (SPSS) (Klecka, Nie, and Hull, 1975) was used to 1) determine the mean extent of the phonational frequency ranges for each vowel by sex, and 2) determine the means of the lowest and highest notes for each vowel by sex. All above procedures were computed on the Honeywell 6220 computing system. 
CHAPTER IV

\section{RESULTS AND DISCUSSION}

\section{$\underline{\text { Results }}$}

\section{Phonational Frequency Ranges}

The purpose of this investigation was to determine the phonational frequency range (PFR) in vocally untrained adults when phonating the cardinal vowels of $/ i /, / u /$, and $/ a /$. The investigation sought to answer the following question: Does the phonational frequency range, in vocally untrained adults vary significantly when phonating the cardinal vowels of $/ i /$, $/ \mathrm{u} /$, and $/ a /$ ? Statistical analyses revealed that no statistically significant differences existed between the extent of the phonational frequency ranges by varying the vowel for either sex group (see Table I). It should be noted, however, that in the female group, the difference between the extent of the ranges for $/ i /$ and $/ a /$ approached a statistically significant difference as the level of significance between these two vowels reached $.055(p<.05)$.

As seen in Table II, overall, for the males, / $i /$ had the widest range $(\bar{x}=572 \pm 167 \mathrm{~Hz})$, followed by $/ a /(x=567 \pm$ $156 \mathrm{~Hz})$, with /u/ having the narrowest range $(\bar{x}=554 \pm 138 \mathrm{~Hz})$. For the females, $/ i /$ had the widest range $(\bar{x}=951 \pm 339 \mathrm{~Hz})$, followed by $/ \mathrm{u} /(\overline{\mathrm{x}}=889+303 \mathrm{~Hz})$, with $/ \mathrm{a} /$ having the 


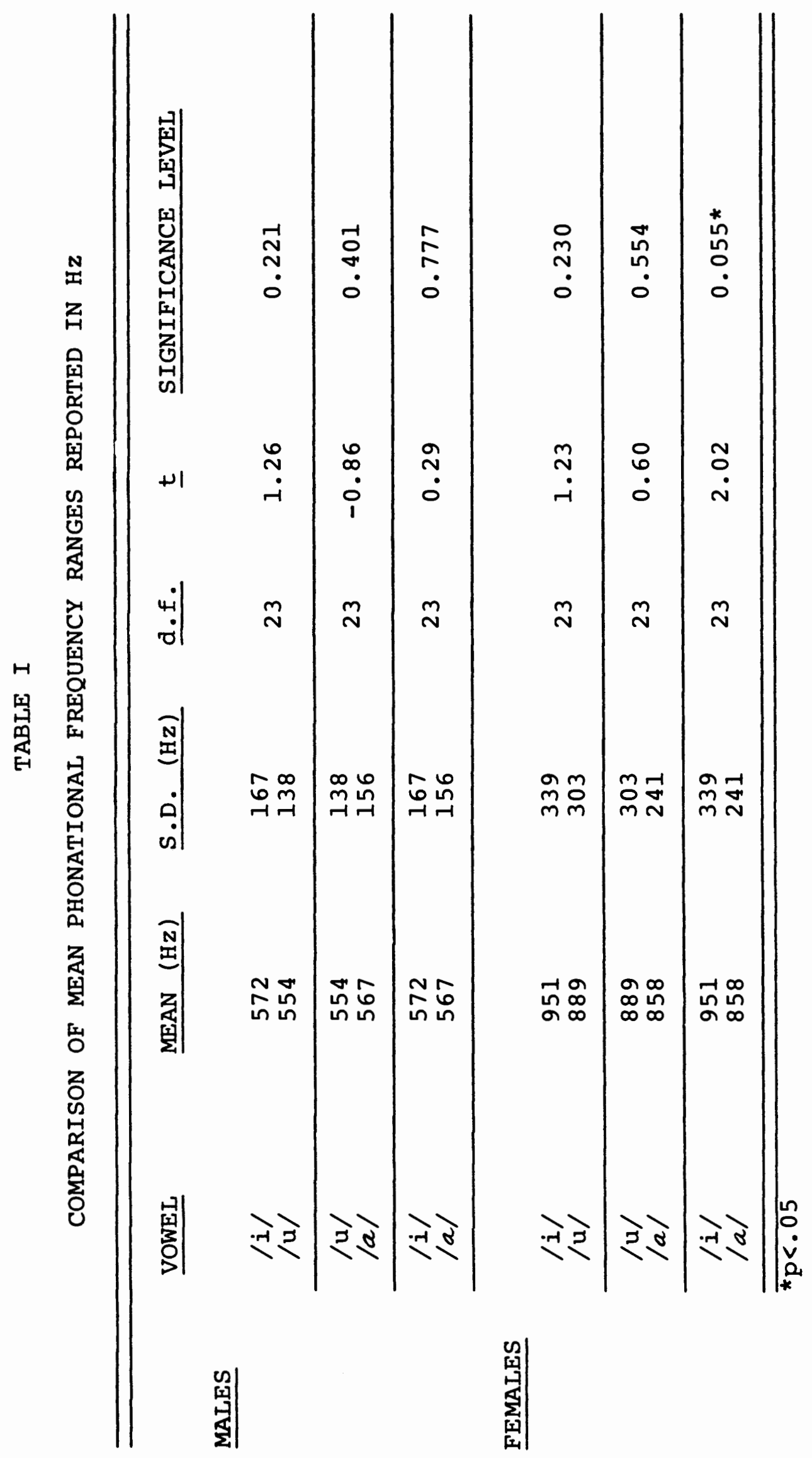




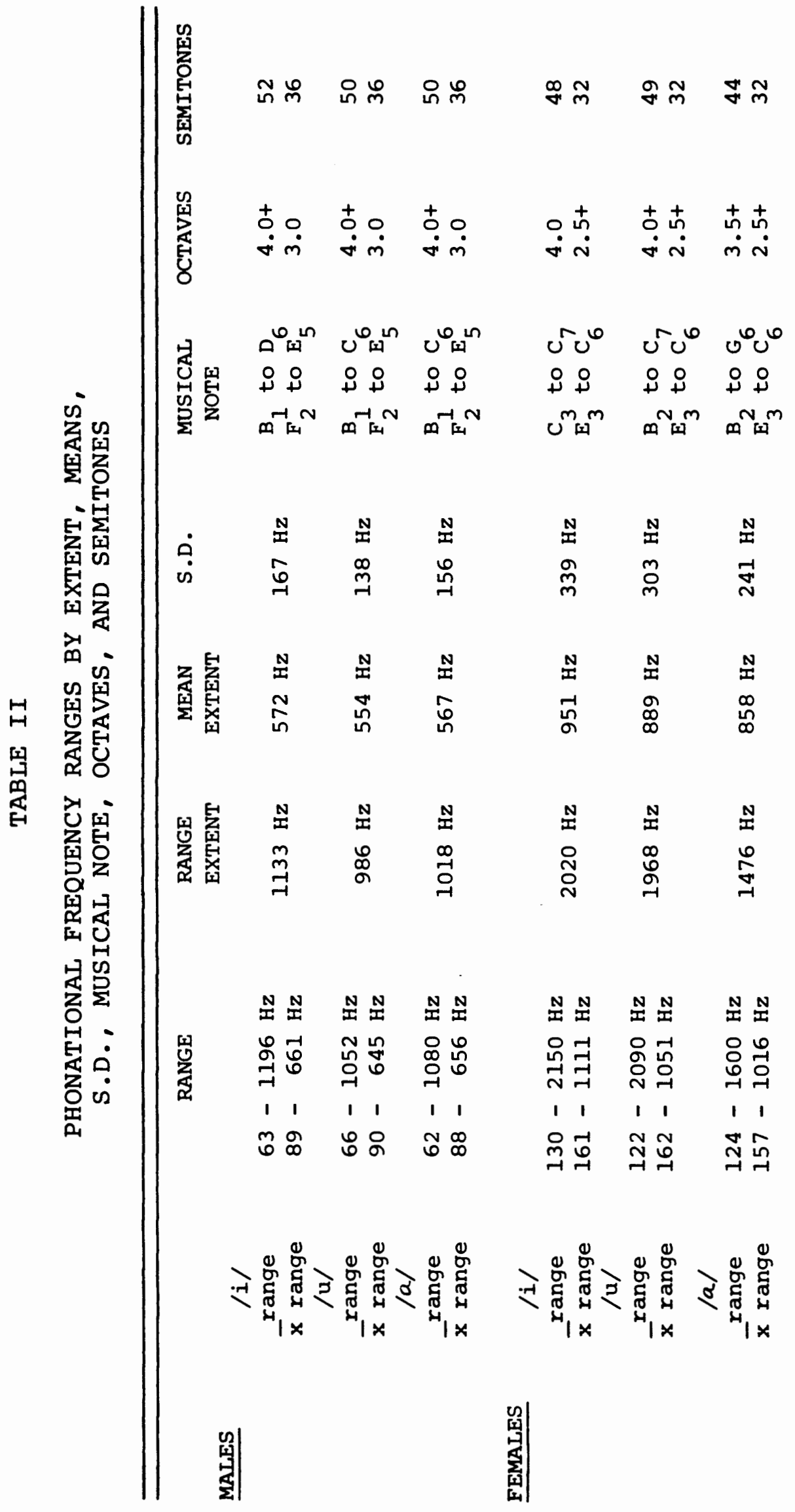


narrowest range $(\bar{x}=858 \pm 241 \mathrm{~Hz})$. Both sex groups phonated lowest on $/ a /$ and highest on $/ i /$, though the difference between the lowest and highest frequencies for all vowels was minimal.

Specifically, in reference to Table II, for males, the PFR using / $i /$ ranged from $63 \mathrm{~Hz}$ to $1196 \mathrm{~Hz}$, or about $\mathrm{B}_{1}$ to $D_{6}$, a range of slightly more than four octaves (fifty-two semitones). The range extended $1133 \mathrm{~Hz}$ with the mean extent of the range being $572 \pm 167 \mathrm{~Hz}$. The overall mean range extended from $89 \mathrm{~Hz}$ to $661 \mathrm{~Hz}$, or about $\mathrm{F}_{2}$ to $E_{5}$ for a mean range of three octaves (thirty-six semitones).

The males' PFR using/u/ ranged from $66 \mathrm{~Hz}$ to $1052 \mathrm{~Hz}$, or about $B_{1}$ to $C_{6}$, a range of slightly more than four octaves (fifty semitones). The range extended $986 \mathrm{~Hz}$ with the mean extent of the range being $554+138 \mathrm{~Hz}$. The overall mean range extended from $90 \mathrm{~Hz}$ to $645 \mathrm{~Hz}$, or about $\mathrm{F}_{2}$ to $\mathrm{E}_{5}$ for a mean range of three octaves (thirty-six semitones).

The PFR for males using /a/ ranged from $62 \mathrm{~Hz}$ to $1080 \mathrm{~Hz}$, or about $B_{1}$ to $C_{6}$, a range of slightly more than four octaves (fifty semitones). The range extended $1018 \mathrm{~Hz}$ with the mean extent of the range being $567 \pm 156 \mathrm{~Hz}$. The overall mean range extended from $88 \mathrm{~Hz}$ to $656 \mathrm{~Hz}$, or about $\mathrm{F}_{2}$ to $\mathrm{E}_{5}$ for a mean range of three octaves (thirty-six semitones).

Also in reference to Table II, for the females, the PFR using /i/ ranged from $130 \mathrm{~Hz}$ to $2150 \mathrm{~Hz}$, or about $c_{3}$ to $C_{7}$, a range of four octaves (forty-eight semitones). The range extended $2020 \mathrm{~Hz}$ with the mean extent of the range being 
$951+339 \mathrm{~Hz}$. The overall mean range extended from $161 \mathrm{~Hz}$ to $1111 \mathrm{~Hz}$, or about $\mathrm{E}_{3}$ to $\mathrm{C}_{6}$ for a mean range of slightly more than two and one-half octaves (thirty-two semitones).

The females' PFR using / u/ ranged from $122 \mathrm{~Hz}$ to 2090 $\mathrm{Hz}$, or about $\mathrm{B}_{2}$ to $\mathrm{C}_{7}$, a range of slightly more than four octaves (forty-nine semitones). The range extended $1968 \mathrm{~Hz}$ with the mean extent of the range being $889+303 \mathrm{~Hz}$. The overall mean range extended from $162 \mathrm{~Hz}$ to $1051 \mathrm{~Hz}$, or about $\mathrm{E}_{3}$ to $c_{6}$ for a mean range of slightly more than two and one-half octaves (thirty-two semitones).

The PFR for the females using /a/ ranged from $124 \mathrm{~Hz}$ to $1600 \mathrm{~Hz}$, or about $B_{2}$ to $G_{6}$, a range of nearly four octaves (forty-four semitones). The range extended $1476 \mathrm{~Hz}$ with the mean extent of the range being $858 \pm 241 \mathrm{~Hz}$. The overall mean range extended from $157 \mathrm{~Hz}$ to $1016 \mathrm{~Hz}$, or about $\mathrm{E}_{3}$ to $\mathrm{C}_{6}$ for a mean range of slightly more than two and one-half octaves (thirty-two semitones).

As shown in Table III, the combined mean ranges for both males and females extended slightly more than three and one-half octaves (forty-three semitones).

Natural Pitch Levels

In addition to phonational frequency ranges being determined, data were collected on natural pitch levels which was not part of the original investigation. Natural pitch level, according to Fairbanks $(1960)$, is the level at which one's voice is used most efficiently for speech. He reports 
TABLE III

COMBINED MEAN RANGES FOR BOTH SEX GROUPS

\begin{tabular}{|c|c|c|c|c|c|c|c|}
\hline \multirow[b]{3}{*}{$/ i /$} & \multirow{3}{*}{$\bar{x}$} & \multirow{3}{*}{$\begin{array}{l}\text { MALE } \\
\text { LOW } \\
89\end{array}$} & \multirow{3}{*}{$\begin{array}{c}\frac{\text { FEMALE }}{\mathrm{X}} \mathrm{HIGH} \\
-\quad 1111 \mathrm{~Hz}\end{array}$} & \multirow{2}{*}{\multicolumn{3}{|c|}{ MUSICAL NOTE }} & \multirow{3}{*}{$\begin{array}{c}\text { SEMITONES } \\
43\end{array}$} \\
\hline & & & & & & & \\
\hline & & & & $\mathrm{F}_{2}$ & to & $\mathrm{c}_{6}$ & \\
\hline$/ \mathrm{u} /$ & & 90 & $-\quad 1051 \mathrm{~Hz}$ & $\mathrm{~F}_{2}$ & to & $\mathrm{c}_{6}$ & 43 \\
\hline$|a|$ & & 88 & - $\quad 1016 \mathrm{~Hz}$ & $\mathrm{~F}_{2}$ & to & $c_{6}$ & 43 \\
\hline
\end{tabular}

this level to be located about one-fourth of the way from the lowest point of the phonational frequency range and states that the mean natural pitch level for men is $c_{3}$ while the mean natural pitch level for women is $\mathrm{C}_{4}$.

As seen in Table IV, natural pitch levels for males phonating / $i /$ ranged from $A_{2}{ }_{2}$ to $G_{3}$ (nine semitones). The majority of the natural pitch levels (six) were at $\mathrm{C}_{3}$ which is one semitone above the Fairbanks (1960) mean. Natural pitch levels for $/ \mathrm{u} /$ ranged from $\mathrm{A \#}_{2}$ to $\mathrm{F \#}_{3}$ (eight semitones). The majority of the natural pitch levels (five) were at $D^{\#} 3$ which is three semitones above the Fairbanks (1960) mean and at $\mathrm{C}_{3}$ (five) which is at his mean. Natural pitch levels for la/ ranged from $A_{2}{ }_{2}$ to $F_{3}$ (seven semitones). The majority of the natural pitch levels (six) were at $F_{3}$ which is five semitones above the Fairbanks (1960) mean and at $D_{3}$ (six) which is two semitones above his mean. The mean natural pitch level of the male subjects for each vowel was at $D_{3}$ which is 
TABLE IV

NATURAL PITCH LEVEL MODES

AND NUMBER OF SUBJECTS FOR EACH NOTE, BY VOWEL

lil lu/ lal

MALES

\begin{tabular}{|c|c|c|c|}
\hline$G_{3}$ & 1 & 0 & 0 \\
\hline $\mathrm{F \#}_{3}$ & 2 & 3 & 0 \\
\hline $\mathrm{F}_{3}$ & 2 & 1 & $6 *$ \\
\hline$E_{3}$ & 1 & 1 & 2 \\
\hline D\# 3 & 2 & $5 *$ & 0 \\
\hline $\mathrm{D}_{3}$ & $3 \bar{x}$ & $2 \bar{x}$ & $6 * \bar{x}$ \\
\hline $\mathrm{C \#}_{3}$ & $6 *$ & 3 & 4 \\
\hline$B_{2}$ & 3 & 2 & 2 \\
\hline $\mathrm{A \#}_{2}$ & 1 & 2 & 1 \\
\hline
\end{tabular}

FEMALES

$\begin{array}{lccc}\mathrm{D}_{4} & 3 & 2 & 2 \\ \mathrm{C \#}{ }_{4} & 2 & 2 & 2 \\ \mathrm{C}_{4} & -9 * \bar{x} & 3 \overline{\mathrm{x}} & 3 \overline{\mathrm{x}} \\ \mathrm{B}_{3} & 3 & 4 & 4 \\ \mathrm{A \#}_{3} & 4 & 3 & 1 \\ \mathrm{~A}_{3} & 3 & 1 & 3 \\ \mathrm{GH}_{3} & 0 & & \end{array}$

* denotes mode

----denotes Fairbanks' (1960) mean

$\overline{\mathbf{x}}$ denotes Chambers' mean 
two semitones above the Fairbanks (1960) mean.

Also in reference to Table IV, natural pitch levels for females phonating / $i /$ ranged from $A_{3}$ to $D_{4}$ (five semitones). The ranges for $/ u /$ and $/ a /$ extended from $G_{3}$ to $D_{4}$ (six semitones). With each vowel, the majority of natural pitch levels (nine for each vowel) were at $c_{4}$ which is at the mean according to Fairbanks (1960). The mean natural pitch level of the female subjects phonating / $i /$ was at $c_{4}$ which is the same as the Fairbanks (1960) mean. For the vowels $/ u /$ and $/ a /$, the natural pitch level was at $B_{3}$ which is one semitone below the Fairbanks (1960) mean.

\section{Discussion}

Phonational Frequency Ranges

This investigation sought to answer the following question: Does the phonational frequency range (PFR) in vocally untrained adults vary significantly when phonating the cardinal vowels of $/ i /, / u /$, and $/ a /$ ? The results indicated no statistically significant differences existed between the extent of the PFR's by varying the vowel for either sex group; however, in the female group, the difference between the extent of the ranges for $/ i /$ and $/ a /$ showed a trend toward significance. The findings from this investigation are in conflict with Vennard's (1967) contention that higher pitches may be reached with rounded vowels (i.e., /u/) as the subjects in this study reached nearly the same frequency regardless of the vowel used. 
In reference to Table $V$, comparing the findings of this investigation with the findings of Hollien, Dew, and Philips (1971), Shipp and McGlone (1971), Hollien and Michel (1968), and Ptacek et al. (1966), who reported their data in mean values, this examiner found the present data to be in reasonable agreement with those studies listed above; all ranges were within six semitones of each other for males and within five semitones for females. One exception is the data reported for females by Hollien and Michel (1968) where if the modal and falsetto mean ranges are added, the phonational frequency range is about three and one-half octaves (fortyfour semitones).

Because no statistically significant differences were found to exist between the various ranges in the present investigation, one may speculate that the overall laryngeal musculature functioning is not greatly affected by vowel variation, at least for the male group. Because there was a trend toward significance between the ranges of $/ i /$ and $/ a /$ for the females, one may reason that this difference may be attributed to the high-positioned, tense production of $/ i /$ and the low-positioned, lax production of $/ a /$. Thus, it may be reasonable to infer that in females, phonational frequency ranges may be influenced by the production of tense versus lax vowels and/or a close versus an open oral cavity.

The combined mean ranges for both sex groups (see Table III) extended slightly more than three and one-half octaves (forty-three semitones). This range is five semitones less 
TABLE V

COMPARISONS OF PHONATIONAL FREQUENCY

RANGES IN OCTAVES AND SEMITONES

ACCORDING TO VARIOUS STUDIES

Investigator (s)

Hollien (1960)*

Hollien (1962)*

Ptacek et al.

(1966)
Males

Octaves/Semitones
Females

Octaves/Semitones

$4.0 / 46$
$3.0 / 41$
$4.0 / 45$

$\begin{array}{lc}\begin{array}{l}\text { young } \\ 2.5+/ 34.5\end{array} & \text { young } \\ \text { old } & 2.5+/ 32.8 \\ 2.0+/ 26.5 & \text { old } \\ & 2.0+/ 25.1\end{array}$

Hollien and Michel

(1968)

pulse

$1.0+/ 14$

modal

$1.5 / 19$

falsetto

$1.0+/ 14$

$3.0+/ 38$

Hollien, Dew, and

Philips (1971)

Shipp and McGlone (1971)

$2.5+/ 32$

No Data

pulse

1. $0+/ 17$

modal

$2.5 / 29$

falsetto

$1.0+/ 15$

$3.0+/ 37$

$/ i /$

$3.0 / 36$

$$
/ \mathrm{u} /
$$

$3.0 / 36$

/a/

$3.0 / 36$ ii/

$2.5+/ 32$

$/ \mathrm{u} /$

$2.5+/ 32$

$|a|$

$2.5+/ 32$

*denotes data not reported in mean values 
than that reported by Brodnitz (1959) who reported four octaves (forty-eight semitones) and twenty-five semitones less than that reported by zemlin (1981) who reported about five and one-half octaves (sixty-eight semitones). It should be noted, however, that the values reported by these authors were not specified as either group or mean values.

Keeping in mind that the mean ranges for both males and females were essentially the same for all vowels, the males exhibited a slightly greater range in semitones over the females by four semitones (thirty-six and thirty-two semitones, respectively). This finding is in agreement with the findings reported by Hollien, Dew, and Philips (1971) and by Ptacek et al. (1966) whose male subjects exhibited PFR's one or two semitones greater than the female subjects. In the present investigation, males exhibited a greater mean range in semitones while the females exhibited a greater range of frequencies. This finding is attributed to the fact that the females reached higher frequencies in their PFR's.

\section{Natural Pitch Levels}

Results from the incidental data collected for natural pitch levels revealed a distribution of natural pitch levels within the same range for both males and females with no apparent affect of vowel variation as the distribution was nearly the same for all vowels. The mean natural pitch levels for both sex groups also was found to be in reasonable agreement with the mean reported by Fairbanks (1960) as the mean 
for the present investigation was within two semitones for the males and within one semitone for the females.

In summary, results from this investigation revealed no statistically significant differences between phonational frequencey ranges when phonating the cardinal vowels of $/ i /$, $/ \mathrm{u} /$, and $/ a / ;$ however, a trend toward statistical significance was noted between the ranges for $/ i /$ and $/ a /$ in the female group. 


\section{CHAPTER V \\ SUMMARY AND IMPLICATIONS}

\section{Summary}

In the clinical management of voice clients, it is important to measure accurate pitch ranges in order to determine if a client has a normal range or is speaking at an optimum pitch. It is not clear from the literature which vowel should be used in determining these pitch ranges. The purpose of this investigation was to determine the phonational frequency ranges in adults with no vocal training when phonating the cardinal vowels of $/ i /, / u /$, and $/ a /$. The investigation sought to answer the following question: Does the phonational frequency range in vocally untrained adults vary significantly when phonating the cardinal vowels of $/ i /, / u /$, and $/ a /$ ?

Twenty-four men and twenty-four women between the ages of twenty and twenty-nine years (mean age 24.1 years), served as subjects. All subjects had voices within the normal range of acceptability and had normal hearing.

The subjects were instructed to sing the musical scale to their lowermost (excluding vocal fry) and uppermost (including falsetto) limits and to sustain their lowest and highest notes for four seconds. The extremes of the ranges 
were audio-recorded and analysed by an oscilloscope and fast Fourier transform spectrum analyser for exact frequencies.

Results from this investigation revealed no statistically significant differences existed between the extent of the phonational frequency ranges by varying the vowel for either sex group; however, in the female group, the difference between the extent of the ranges for $/ i /$ and $/ a /$ showed a trend toward significance as the level of significance between these two vowels reached .055 (p<.05) (d.f.=23).

The males' mean PFR using / $i /$ extended from $89 \mathrm{~Hz}$ to $661 \mathrm{~Hz}$, or about $\mathrm{F}_{2}$ to $\mathrm{E}_{5}$ for a mean range of three octaves (thirty-six semitones). Their mean PFR using / $\mathrm{u} /$ extended from $90 \mathrm{~Hz}$ to $645 \mathrm{~Hz}$, or about $\mathrm{F}_{2}$ to $\mathrm{E}_{5}$ for a mean range of three octaves (thirty-six semitones). The mean PFR using /a/ extended from $88 \mathrm{~Hz}$ to $656 \mathrm{~Hz}$, again about $\mathrm{F}_{2}$ to $\mathrm{E}_{5}$ for a mean range of three octaves (thirty-six semitones).

The females' mean PFR using / $i /$ extended from $161 \mathrm{~Hz}$ to $11 l \mathrm{~Hz}$, or about $\mathrm{E}_{3}$ to $\mathrm{C}_{6}$ for a mean range of slightly more than two and one-half octaves (thirty-two semitones). Their mean PFR using/u/ extended from $162 \mathrm{~Hz}$ to $1051 \mathrm{~Hz}$, or about $E_{3}$ to $C_{6}$ for a mean range of slighly more than two and one-half octaves (thirty-two semitones). The mean PFR using la/ extended from $157 \mathrm{~Hz}$ to $1016 \mathrm{~Hz}$, again about $\mathrm{E}_{3}$ to $\mathrm{C}_{6}$ for a mean range of two and one-half octaves (thirty-two semitones).

Data were also collected on natural pitch levels, 
although not a part of the original investigation. Natural pitch levels for males ranged from $A_{2} \#_{2}$ to $G_{3}$ for all vowels with a mean natural pitch level at $\mathrm{D}_{3}$ for all vowels.

Natural pitch levels for females ranged from $\mathrm{G}_{3}$ to $\mathrm{D}_{4}$ for all vowels with a mean natural pitch level at $c_{4}$ for $/ i /$ and at $B_{3}$ for $/ \mathrm{u} /$ and $/ a /$.

\section{Implications}

Clinical

Results from this investigation revealed no statistically significant differences in phonational frequency ranges when the cardinal vowels of $/ i /, / u /$, and $/ a /$ were phonated; thus, it may be reasonable to imply that the use of these vowels to determine PFR's will yield similar results. These data should be interpreted with caution, however, due to the relatively small sample size.

Results from this study are consistent with previous data; therefore, clinicians may determine PFR's and compare ranges with these data to judge normalcy.

Information from this investigation also may be used to determine natural pitch levels and the level of optimal functioning of the vocal mechanism for speech. As revealed in this study, vowel variation did not appear to affect the distribution of natural pitch levels; therefore, if phonational frequency ranges were determined using $/ i /$ or $/ u /$, the clinician may find similar results as when using $/ a /$. Again, caution should be exercised when interpreting results. 
Research

It appears there is little difference in the PFR when phonating $/ i /, / u /$, or $/ a / i$ however, since the difference between the ranges in the female group for / $i /$ and /a/ approached a statistically significant difference, further investigation is indicated for comparison of these two vowels.

Ptacek et al. (1966) found a decrease in the PFR's with advancing age; therefore, it may be clinically useful to replicate the present investigation with other age groups, both younger and older, to determine if age and vowel variation will affect the PFR.

Though Hollien, Dew, and Philips (1971) found that some untrained singers have ranges just as extensive as trained singers, it may be enlightening to determine the PFR of trained singers phonating $/ i /$ and $/ u /$ and compare those ranges to the range using $/ a /$.

Finally, since according to Vennard (1967), Husler and Rodd-Marling (1967) and Negus (1930) there is different laryngeal muscle activity during the production of vowels, it is suggested that an investigation be carried out to measure laryngeal muscle activity, as described by Shipp and McGlone (1971), during vowel production at specified pitch levels and to measure laryngeal dimensions as subjects phonate $/ i /, / u /$, and $/ a /$ at specific points in their PFR's as described by Hollien (1960). 


\section{BIBLIOGRAPHY}

ANDERSON, V., Training the speaking Voice. New York: Oxford University Press (1942).

ANDERSON, V., Training the speaking Voice. (3rd ed.) New York: Oxford University Press (1977).

APPELMAN, D., The Science of Vocal Pedagogy: Theory and Application. Bloomington, Indiana: Indiana University Press (1967).

BOONE, D., The Voice and Voice Therapy. Englewood Cliffs, New Jersey: Prentice-Hall, Inc. (1971).

BRODNITZ, F., Vocal Rehabilitation. Rochester, Minnesota: Whiting Press, Incorporated (1959).

DENES, P. and PINSON, E., The Speech Chain: The Physics and Biology of spoken Language. Garden City, New York: Anchor Books (1963).

FAIRBANKS, C., Voice and Articulation Drillbook. (2nd ed.) New York: Harper and Row, Publishers (1960).

HANLEY, T. and THURMAN, W., Developing Vocal Skills. New York: Holt, Rinehart and Winston (1962).

HOLLIEN, H., Some laryngeal correlates of vocal pitch. Journal of Speech and Hearing Research, 1960, 3(1), 52-58.

HOLLIEN, H., Vocal fold thickness and fundamental frequency of phonation. Journal of Speech and Hearing Research, $1962,5(3), 237-243$.

HOLLIEN, $\mathrm{H} .$, The registers and ranges of the voice. In Cooper, M. and Cooper, M. (Eds.), Approaches to Vocal Rehabilitation. Springfield, Illinois: Charles C. Thomas, Publisher (1977).

HOLLIEN, H., DEW, D., and PHILIPS, P., Phonational frequency ranges of adults. Journal of speech and Hearing Research, $1971,14,7 \overline{55-760 .}$

HOLLIEN, H. and MICHEL, J., Vocal fry as a phonational register. Journal of Speech and Hearing Research, 1968, 11, $600-60 \overline{4}$. 
HUSLER, F., and RODD-MARIING, Y., Singing: The Physical Nature of the Vocal Organ. New York: October House, Inc. (1964).

JONES, D., An Outline of English Phonetics. (9th ed.) Cambridge, England: W. Heffer and Sons LTD., (1960).

KLECKA, W., NIE, N., and HULL, C., SPSS Primer: Statistical Package for the Social Sciences Primer. McGraw-Hill Book Company (1975).

LEUTENEGGER, R., The Sounds of American English: An Introduction to phonetics. Glenview, Illinois: Scott, Foresman and Company (1963).

LUCHSINGER, R. and ARNOLD, G., Voice-Speech-Language, Clinical Communicology: Its Physiology and Pathology. Belmont, California: Wadsworth Publishing Company, Inc. (1965).

MEANO, C., and KHOURY, A., The Human Voice in Speech and Song. Springfield, Illinois: Charles C. Thomas, Publisher (1967).

NEGUS, V., The Mechanism of the Larynx. St. Louis: The C.V. Mosby Company (1930).

PTACEK, P., SANDER, E., MALONEY, W., and JACKSON, C., Phonatory and related changes with advanced age. Journal of Speech and Hearing Research, 1966, 9, 353-360.

SHIPP, T. and MCGLONE, P., Laryngeal dynamics associated with voice frequency change. Journal of Speech and Hearing Research, 1971, 14, 761-768.

VENNARD, W., Singing: The Mechanism and the Technic. (5th ed.) Cooper Square, New York: Carl Fischer, Inc. (1967).

WILSON, K., The voice-disordered child: A descriptive approach. Language, Speech and Hearing Services in Schools, 1971, 1, 14-22.

ZEMLIN, W., Speech and Hearing Sciences. (2nd ed.) Englewood Cliffs, New Jersey: Prentice-Hall, Inc. (1981). 


\section{APPENDIX A \\ SUBJECT ELIGIBILITY SCREENING}

Are you a smoker or non-smoker? -- must be a non-smoker.

How old are you? -- must be twenty to twenty-nine years of age.

Have you had any formal vocal training in music since high school? -- must not have had such training.

Do you actively participate in any singing groups? -- must not be a participant.

Have you had any history of a voice disorder? -- If yes, when? Diagnosis? Treatment? -- must be free of vocal pathology.

Do you presently have a cold or sore throat? Do you have any respiratory allergies? -- must be free of illness.

Do you experience vocal strain or fatigue on a regular basis? For example, using your voice on your job or other to an extent to cause strain or fatigue. -- must not experience vocal strain or fatigue regularly on the day of the recording.

Demonstrates ability to follow a series of descending and ascending notes when accompanied by the piano. 


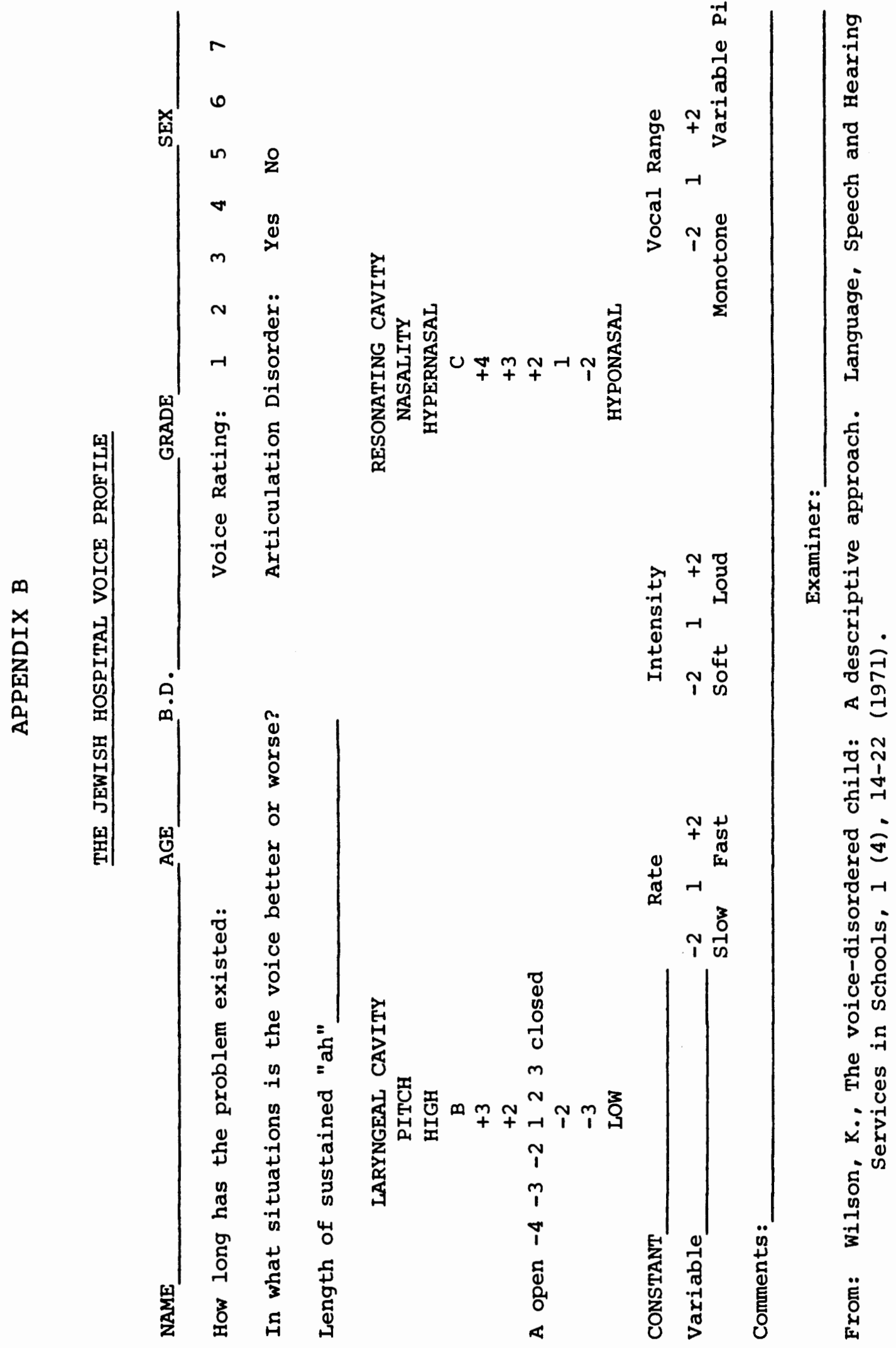




\section{APPENDIX C}

\section{FATREANRS MUSICAL SCALE PITCH LEVER COMARISON}

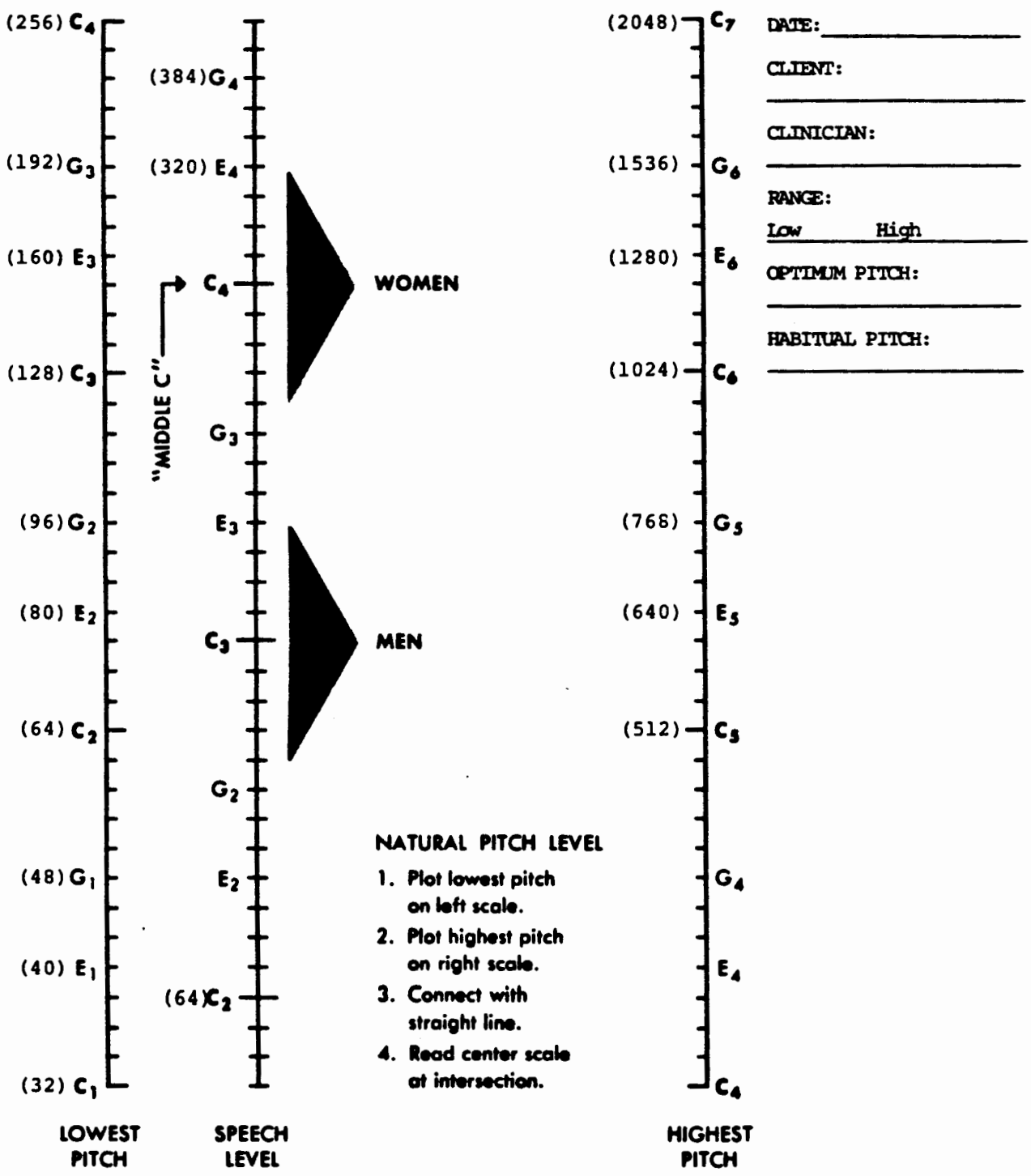

After: Fairbanks, G. VICE AND ARIICULATION DRTILBOOK. New York: Harper \& Row, 1960. 


\section{APPENDIX D}

\section{"RAINBOW PASSAGE"}

Paragraph excerpted from: Fairbanks, G., Voice and Articulation Drillbook. New York: Harper \& Row (1960).

When the sunlight strikes raindrops in the air, they act like a prism and form a rainbow. The rainbow is a division of white light into many beautiful colors. These take the shape of a long round arch, with its path high above, and its two ends apparently beyond the horizon. There is, according to legend, a boiling pot of gold at one end. People look, but no one ever finds it. When a man looks for something beyond his reach, his friends say he is looking for the pot of gold at the end of the rainbow. 


\section{APPENDIX E}

SPECIFICATIONS

Ampex AG-500 Tape Recorder

The Ampex AG-500 tape recorder was operated at a tape speed of 7-1/2 ips. Flutter and wow (using flutter tape test), measured according to ASA standard 257.1-1954, is $0.138 \mathrm{rms}$ at $7-1 / 2$ ips. Frequency response (500 reference) at $7-1 / 2$ ips is $\pm 2 \mathrm{~dB}$ for 60 to $10,000 \mathrm{~Hz}$ and $+2-4 \mathrm{~dB}$ for 30 to $50,000 \mathrm{~Hz}$. The Signal-to-Noise Ratio at $7-1 / 2$ ips for halftrack head assembly is $55 \mathrm{~dB}$.

Tektronix Portable Oscilloscope, No. 485

The 485 is a general-purpose environmentalized, high-performance, portable, wide-band oscilloscope which has a dual-channel vertical amplifier with selectable input impedance (DC to $350 \mathrm{MHz}$ bandwidth with $50 \Omega$ input impedance; DC to $250 \mathrm{MHz}$ bandwidth with $1 \mathrm{M} \Omega$ input impedance). The 485 has a 1 ns sweep rate, stable triggering to bandwidth limits and calibrated $X-Y$ capabilities. Delayed sweep has calibrated delay time, can be triggered after delay and can be displayed with the intensified main sweep in an alternate sweep switching display. Additional features are X10, X100 probe scale factor readout, 8 div Xlo graticule area, small spot size and high writing rate. A $20 \mathrm{MHz}$ bandwidth limiter, $1 \mathrm{MHz}$ and $1 \mathrm{kHz}$ fast-rise calibrator and autofocus are also included. The $50 \Omega$ input is automatically disconnected from excessive voltages. An external trigger view feature is also provided. (This information is excerpted verbatim from instruction manual.) 
Princeton Applied Research fast Fourier transform (FFT) Spectrum Analyser, No. 4512

The 4513 FFT Real Time Spectrum Analyser uses a fast Fourier transform (FFT) technique to determine the spectral content of signals (and noise) occurring in industrial and scientific applications such as acoustics, vibration analysis, musicology, signature analysis, noise analysis, fluid dynamics, biomedical signal analysis, and communications. Usable with either continuous or transient signals, the analyser can display an input signal and its spectrum either simultaneously or separately, on any commercial oscilloscope. In addition, a recorder can be used to obtain a permanent record of the captured signal and/orits spectrum. A digital output is also provided for further analysis by a digital computer or post processor. Frequency and point magnitude determinations are facilitated by inclusion of a positional cursor and a digital display. For maximum flexibility, the transform analysis can either be synchronized with the signal capture or occur independent of it. The 4512 requires only $33 \mathrm{~ms}$ to do a complete fast Fourier transform, providing extremely efficient real time utilization. . There are twelve analysis ranges, the lowest being dc-10 $\mathrm{Hz}$, and the highest dc to $40 \mathrm{kHz}$. . . Input signals are sampled by a 12 bit $\mathrm{A} / \mathrm{D}$ Converter and stored in an input memory. (This information is excerpted verbatim from instruction manual.) 